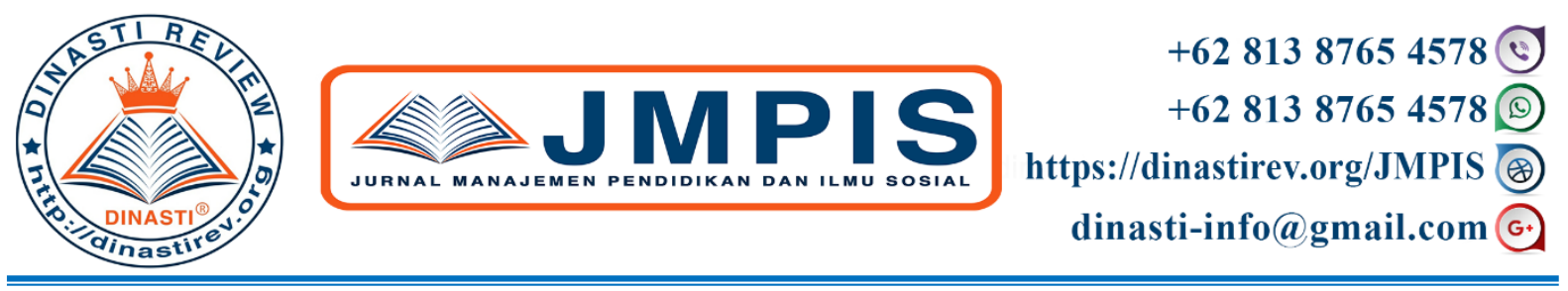

\title{
PENGARUH PENDIDIKAN EKONOMI KELUARGA, TEMAN PERGAULAN TERHADAP LITERASI EKONOMI MAHASISWA UNIVERSITAS JAMBI
}

\author{
Afrianti ${ }^{1)}$ \\ 1) Alumni Program Magister Pendidikan Ekonomi Univeritas Jambi, Jambi, Indonesia
}

\begin{tabular}{|c|c|}
\hline $\begin{array}{l}\text { ARTICLE INFORMATION } \\
\text { Received: } 27 \text { Juni } 2020 \\
\text { Revised: } 30 \text { Juni } 2020 \\
\text { Issued: } 10 \text { Juli } 2020 \\
\text { Corresponding author: first author } \\
\text { E-mail: } \\
\text { afrianti.spd87@gmail.com }\end{array}$ & 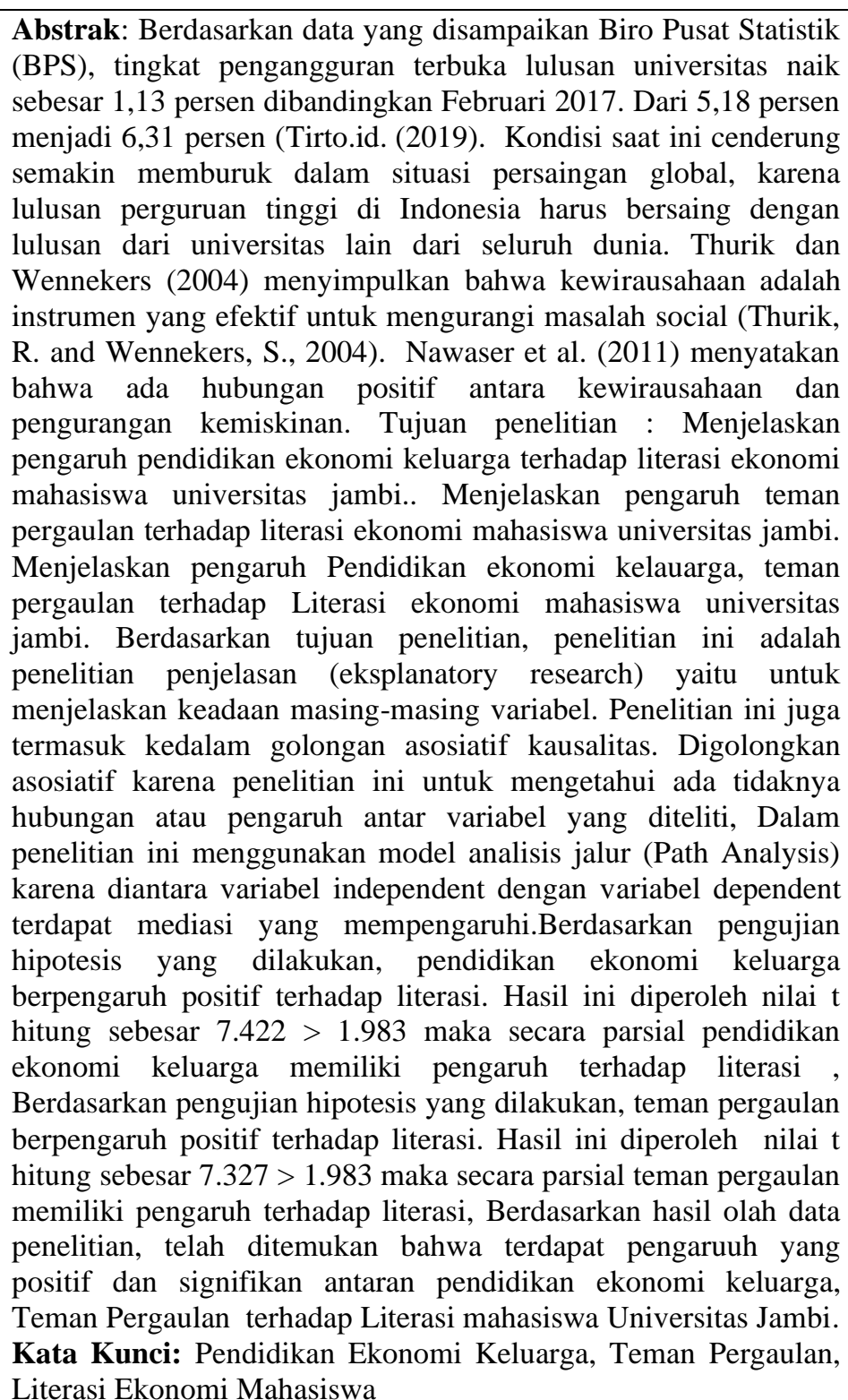 \\
\hline
\end{tabular}

\section{PENDAHULUAN}

Saat ini jumlah pengangguran intelektual di Indonesia masih terbilang tinggi, yang disebabkan kesempatan kerja yang terbatas untuk lulusan perguruan tinggi. Berdasarkan data 
yang disampaikan Biro Pusat Statistik (BPS), tingkat pengangguran terbuka lulusan universitas naik sebesar 1,13 persen dibandingkan Februari 2017. Dari 5,18 persen menjadi 6,31 persen (Tirto.id., 2019). Kondisi saat ini cenderung semakin memburuk dalam situasi persaingan global, karena lulusan perguruan tinggi di Indonesia harus bersaing dengan lulusan dari universitas lain dari seluruh dunia. Thurik dan Wennekers (2004) menyimpulkan bahwa kewirausahaan adalah instrumen yang efektif untuk mengurangi masalah social (Thurik, R. and Wennekers, S., 2004). Nawaser et al. (2011) menyatakan bahwa ada hubungan positif antara kewirausahaan dan pengurangan kemiskinan. Demikian juga dinyatakan Jones dan Colwill (2013) bahwa banyak literatur kewirausahaan telah mengakui bahwa pendidikan kewirausahaan mampu mengatasi masalah pengangguran lulusan. Penelitian ini tidak akan membahawan bagaimana pengaruh pendidikan kewirausahaan terhadap pengembangan kewirausahaan, karena hal ini telah banyak diteliti diantaranya Suratno dkk (2019), melainkan niat kewirausahaan dalam hubungannya dengan pendidikan ekonomi yang diterima seorang mahasiswa dalam keluarga, lingkungan pergaulan yang dialami, dan literasi ekonomi yang dimiliki.

Pengetahuan ekonomi dasar yang telah dipelajari sejak dari Sekolah Menengah Pertama (SMP) hingga Pergutuan Tinggi (PT) dirancang untuk memberikan pengetahuan dasar bidang ekonomi yang seharusnya diterapkan dalam kehidupannya (Salemi 2003). Pengetahuan ekonomi dasar menyediakan individu suatu dasar bagaimana seharusnya soerang individu berperilaku dalam kehidupan ekeonomi. Dengan pemahaman ekonomi atau letarasi ekonomi maka seseorang dalam berperilaku ekonomi akan bertindak secara rasional.

Literasi ekonomi menurut National Council on Economic Education (NCEE), adalah suatu kondisi yang menggambarkan seseorang dapat memahami permasalahan dasar ekonomi secara baik, sehingga dapat melakukan kegiatan ekonomi dengan benar (Murniatiningsih, 2017). Sedangkan Budiwati dan Rahayu (2018) menyatakan bahwa setiap orang harus mampu mengambil keputusan dalam rangka mencapai kemakmuran ekonomi dengan mengelola masalah-masalah ekonomi dasar, yang asal mulanya dari masalah kelangkaan. Oleh sebab itu pengetahuan ekonomi dasar di bidang ekonomi untuk menyediakan siswa dan mahasiswa yang menjadi dasar studi lebih lanjut. Tujuan lain pembelajaran ekonomi dasar adalah untuk membekali seseorang untuk mencapai pemahaman yang lebih dalam dan pengetahuan kerja dari daftar pendek konsep ekonomi. Pengetahuan ekonomi dasar karenanya, akan membantu seseorang menjadi paham ekonomi dalam arti bahwa mereka dapat menerapkan prinsip dasar ekonomi.

Dalam hubungannya dengan niat atau intensi mahasiswa untuk berwira usaha, pengetahuan dasar ekonomi akan memberikan dasar perilaku ekonomi lebih lanjut untuk melakukan atau tidak melakukan sesuatu secara rasional untuk mencapai kemakmurannya. Oleh sebab itu diduga ada keterkaitan yang kuat antara literasi ekonomi seseorang mahasiswa dengan niatnya untuk berwira usaha. Literasi ekonomi mesti dimiliki setiap indivindu sebagai upaya pendukung pengambilan keputusan terkait ekonomi dengan tepat sehingga mampu dipraktekkan secara langsung pada konteks kewirausahaan (Wulandari,2011).

Mahasiswa sebagai orang dewasa muda yang menjadi obyek penelitian ini berasal dari keluarga dengan berbagai latar belakang yang tidak serupa.. Keluarga juga memiliki handil besar untuk pemberian pendidikan hidup bermasyarakat sehingga mampu menerima, 
mengolah, serta mewarisi kebudayaan. Mahasiswa telah dianggap sebagai orang dewasa muda yang berkembang kearah kesempurnaannya (Djauharah, et al. 1994).

Pendidikan yang diberikan keluarga akan memberikan arah kepada kondisi kemakmuran yang diharapkan anak di masa depan. Pendidikan yang diberikan keluarga akan memberikan arah kepada kondisi kemakmuran yang diharapkan anak di masa depan. oleh karena itu sangat diperlukan peran keluarga didalam pembinaan moral remaja terutama apalagi di era globalisasi menjadikannya bukanlah yang peran singkat dan seadanya. Indivindu - indivindu sebagai anggota keluarga mempunyai tangggung jawab untuk saling memberikan perhatian kepada anggota keluarga lainnya. Dalam hubungan ini, kemakuran yang dimaksudkan diukur secara ekonomi yaitu terciptanya individu yang makmur dan sejatera. Hal ini sejalan dengan Wainwright and Marandet (2017) bahwa keluarga adalah contoh dari inisiatif pendidikan, terutama ditujukan kepada mahasiswa sebagai anak dan terkait dengan masalah kebijakan yang lebih luas. Lebih jauh disampaikan bahwa pembelajaran keluarga - rumah, sekolah, pekerjaan, komunitas dan bangsa - memungkinkan kita untuk melihatnya bagaimana inisiatif dikembangkan. Oleh sebab itu pendidikan ekonomi dalam keluarga akan berkontribusi terhadap pemahaman literasi ekonomi sehingga menumbuhkan inisiatif karier yang akan dipilihnya, dalam hal ini niat berwira usaha. Melalui keluarga orang akan belajar literasi, bahasa dan angka (FLLN-Family Learning Literacy, Language and Numeracy) dan pembelajaran keluarga yang lebih luas. Pendidikan keluarga telah dikaitkan dengan 'keterampilan seumur hidup', ketenagakerjaan, strategi investasi keterampilan dasar dan terkait dengan masalah kebijakan yang lebih luas termasuk perluasan partisipasi, pengembangan kapasitas masyarakat, pembaruan lingkungan dan regenerasi. Pembelajaran keluarga dengan demikian diposisikan sebagai penghubung dari berbagai bidang kebijakan, dengan fokus di luar pendidikan formal (Wainwright \& Marandet, 2013). Bahkan Huges (2019) melalui penelitiannya di Afrika berkesimpulan banyak perilaku transaksional yang dilakukan remaja perempuan didorong dan didukung oleh anggota keluarganya. Ruang lingkup bergaul anak sangat kuat eratannya terhadap tingkah laku anak(Suratno,2014). Lingkungan pergaulan sosial dalam arti prersahabatan, dalam hal intensitas perjumpaan dan kualitas kepuasan dengan hubungan pertemanan, secara positif terkait dengan kepuasan hidup (Amati, et.all. 2018) banyak memberikan warna pada kehiduapnnya, termasuk juga dalam pengambilan keputusan niat untuk melakukan kegiatan wirausaha. Schute (2014) berdasarkan penelitian yang telah dilakukan menggunakan Data Longitudinal berkesimpulan dalam jangka panjang terbukti bahwa lingkungan sosial berpengaruh terhadap terhadap kecerdasan emosi mahasiswa (Schutte, 2014) termasuk juga dalam pengambilan keputusan untuk berwira usaha. Berdasarkan rumusan masalah maka tujuan penelitian ini adalah: Menjelaskan pengaruh pendidikan ekonomi keluarga terhadap literasi ekonomi mahasiswa universitas jambi.. Menjelaskan pengaruh teman pergaulan terhadap literasi ekonomi mahasiswa universitas jambi. Menjelaskan pengaruh Pendidikan ekonomi kelauarga, teman pergaulan terhadap Literasi ekonomi mahasiswa universitas jambi. Defenisi Konseptual yang terdapat pada penelitian ini yaitu sebagai berikut : Pendidikan ekonomi keluarga adalah: suatu kajian tentang upaya manusia dalam memenuhi kebutuhankebutuhanya melalui aktivitas-aktivitas yang dilakukan oleh seseorang yang bertanggungjawab atas kebutuhan dan kebahagiaan bagi hidupnya . Teman pergaulan adalah: hubungan interaksi sosial yang didasarkan pada persamaan usia, status sosial, kebutuhan serta 
minat yang seiring berjalanya waktu akan membentuk pertemanan dan persahabatan, Literasi Ekonomi adalah: pemahaman dan pengetahuan seseorang mengenai dasar teori ekonomi, konsep dan pengaplikasian. Defenisi Operasional : 1) Literasi Ekonomi 2)Pendidikan ekonomi 3) Teman Pergaulan

\section{KAJIAN PUSTAKA}

\section{Literasi Ekonomi}

Menurut Mathews (1999:2) Literasi ekonomi merupakan istilah yang digunakan untuk memberikan gambaran kemampuan individu agar dapat mengenali serta menggunkan konsep ekonomi, serta cara berfikir ekonomi dalam rangka meningkatkan kesejahteraan

\section{Pendidikan Ekonomi Keluarga}

Pendidikan ekonomi keluarga merupakan abstraksi gambaran atau ide dalam proses mengajarkan dan memberikan contoh yang baik untuk merubah perilaku seseorang dalam hal ekonomi dengan tujuan menunjukkan perilaku ekonomi yang baik.

\section{Teman Pergaulan}

Menurut Abdullah Pergaulan atau kontak langsung antara pendidik dan anak didik ini memungkinkan timbulnya cinta pada anak dari pendidik atau sebaliknya. Dan pergaulan juga memungkinkan pengertian yang mendalam antara tugas pendidikan, yang wajib mendidik dan tugas anak didik, yang minta pertolongan atau pendidikan, sehingga dapat menimbulkan sikap yang wajar dan obyektif pada keduanya. Dalam pergaulan itu pendidik dapat mengobservasi anak secara langsung, untuk menemukan potensi-potensi yang ada pada anak didik dan sebaliknya. Saling mengetahui karena pergaulan ini memudahkan usaha bimbingan dan pertolongan dilaksanakan dengan sebaik-baiknya

\section{Kerangka Pemikiran}

Kerangka berfikir digunakan untung menghubungkan atau menjelaskan secara konsep tentang suatu topik yang akan dibahas

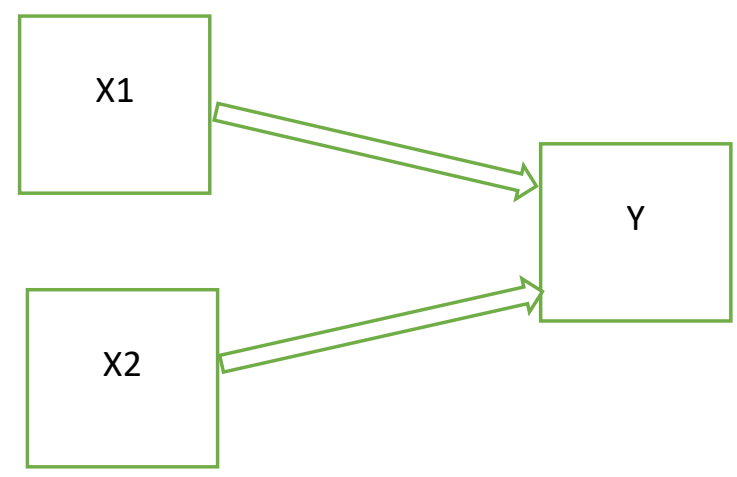

Gambar 1. Kerangka Berpikir

$\mathrm{X}_{1}$ : Pendidikan Keluarga

$\mathrm{X}_{2}$ : Teman pergaulan

Y : Literasi Ekonomi 


\section{Hipotesis}

Berdasarkan rumusan masalah dan beberapa asumsi yang dikemukakan, maka hipotesis yang merupakan dugaan sementara, berdasarkan pada kerangka pemikiran maka hipotesis penelitian yang diajukan adalah:

H1. Pendidikan ekonomi keluarga berpengaruh terhadap Literasi ekonomi mahasiswa universitas jambi.

H2. Teman pergaulan berpengaruh terhadap Literasi ekonomi mahasiswa universitas jambi.

H3. Pendidikan ekonomi dan Teman pergaulan literasi ekonomi berpengaruh terhadap literasi ekonomi mahasiswa universitas jambi.

\section{METODE PENELITIAN}

\section{Desain Penelitian}

Dilihat dari rumusan penelitian ini merupakan penelitian penjelasan (eksplanatory research) yaitu untuk menjelaskan keadaan masing-masing variabel. Penelitian ini juga termasuk kedalam golongan asosiatif kausalitas. Digolongkan asosiatif karena penelitian ini untuk mengetahui ada tidaknya hubungan atau pengaruh antar variabel yang diteliti, Dalam penelitian ini menggunakan model analisis jalur (Path Analysis) karena diantara variabel independent dengan variabel dependent terdapat mediasi yang mempengaruhi.

\section{Populasi dan Sampel}

Menurut Sugiyono (2012) yang dimaksud populasi adalah wilayah generalisasi yang terdiri atas objek ataupun subjek yang mempunyai kualitas serta karakteristik tertentu yang ditetapkan oleh peneliti untuk dipelajari dan ditarik kesimpulannya. Populasi dalam penelitian ini adalah seluruh mahasiswa universitas jambi. Berdasarkan perhitungan menurut Slovin dari jumlah populasi yang dilihat di PDDikti unja pada data pelaporan tahun 2019/2020 sebesar 35295 didapat sampel sebesar 100 mahasiswa yang dijadikan sampel penelitian.

\section{Uji Prasyarat}

Uji Prasyarat untuk menentukan data tersebut bisa dipakai untuk tahap teknis analisis data yaitu menggunakan Uji Normalitas, Uji Multikoliniritas, Uji Heterogenitas.

\section{Teknik Analisis Data}

Peneliti melakukan analisa terhadap data yang telah diuraikan dengan menggunakan metode kualitatif dan metode kuantitatif dengan menggunakan uji instrument penelitian, uji asumsi klasik, persamaan regresi linear berganda, koefisien determinasi, uji parsial dan uji simultan.

\section{HASIL DAN PEMBAHASAN}

Hasil Pengumpulan Data

Pendidikan Ekonomi dalam Keluarga 
Berdasarkan hasil olahan data SPSS versi 22 tentang pendidikan ekonomi dalam keluarga dari data pada tabel 4.1 diketahui nilai minimum adalah 21; nilai maksimum adalah 36; mean adalah 29.62; standar deviasi adalah 3.809.

\section{Teman Pergaulan}

Berdasarkan hasil olahan data SPSS versi 22 tentang teman pergaulan dalam keluarga dari data pada tabel 4.1 diketahui nilai minimum adalah 28; nilai maksimum adalah 52; mean adalah 41.07; standar deviasi adalah 5.083.

\section{Literasi Ekonomi}

Berdasarkan hasil olahan data SPSS versi 22 tentang literasi ekonomi dalam keluarga dari data pada tabel 4.1 diketahui nilai minimum adalah 12; nilai maksimum adalah 48; mean adalah 38.94; standar deviasi adalah 4.958 .

\section{Hasil Uji Prasyarat}

\section{Uji Normalitas}

Pada prinsipnya normalitas dapat dideteksi dengan melihat penyebaran data (titik) pada sumbu diagonal dari grafik. Namun pada dasarnya uji normalitas dengan grafikpun dapat menyesatkan apabila tidak hati-hati secara visual kelihatan normal, padahal secara statistic bisa sebaliknya. Oleh sebab itu uji normalitas dalam penelitian ini penulis menggunakan uji statistic, dimana outputnya dapat dilihat pada Tabel 4.2

Tabel 1. Hasil Uji Normalitas

One-Sample Kolmogorov-Smirnov Test

\begin{tabular}{|c|c|c|c|}
\hline & & & $\begin{array}{c}\text { Unstandardized } \\
\text { Residual }\end{array}$ \\
\hline $\begin{array}{l}\text { N } \\
\text { Normal Parameters }{ }^{a, b} \\
\text { Most Extreme Differences } \\
\text { Test Statistic } \\
\text { Asymp. Sig. (2-tailed) } \\
\text { Monte Carlo Sig. (2-tailed) }\end{array}$ & $\begin{array}{l}\text { Mean } \\
\text { Std. Deviation } \\
\text { Absolute } \\
\text { Positive } \\
\text { Negative } \\
\text { Sig. } \\
\text { 99\% Confidence Interval }\end{array}$ & 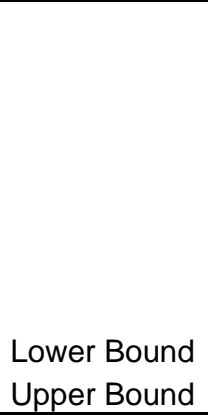 & $\begin{array}{r}100 \\
.0000000 \\
1.73308839 \\
.110 \\
.080 \\
-.110 \\
.110 \\
.005^{\mathrm{c}} \\
.170^{\mathrm{d}} \\
.161 \\
.180\end{array}$ \\
\hline
\end{tabular}

Dari uji normalitas yang menggunakan SPSS 22 diperoleh hasil yang disajikan pada Tabel 1 dengan menggunakan metode One Sample Kolmogrov Smirnov. Dimana didapat hasil tes hitung sebesar 0,170. Jika nilai signifikan lebih besar dari 0,05, maka data tersebut berdistribusi normal (priyatno, 2012). Maka semua variabel didalam penelitian ini dinyatakan semua berdistribusi normal.

\section{Uji Heteroskedastisitas}

Uji heterokedastisitas berfungsi untuk mengetahui ada atau tidaknya penyimpangan asumsi klasik yang berupa ketidaksamaan varian dari residu untuk semua pengematan pada model regresi. Pengujian heteroskedastisitas didalam penelitian ini menggunkan program 
SPSS 22. Berdasarkan hasil olah data yang didapat melalui uji Glejser sebagaimana disajikan pada Tabel 2 berikut.

Tabel 2. Hasil Uji Heterokedastistias Uji Glejser Coefficients $^{\mathrm{a}}$

\begin{tabular}{|c|c|c|c|c|c|c|}
\hline \multirow{2}{*}{\multicolumn{2}{|c|}{ Model }} & \multicolumn{2}{|c|}{ Unstandardized Coefficients } & \multirow{2}{*}{$\begin{array}{c}\begin{array}{c}\text { Standardized } \\
\text { Coefficients }\end{array} \\
\text { Beta }\end{array}$} & \multirow[b]{2}{*}{$\mathrm{t}$} & \multirow[b]{2}{*}{ Sig. } \\
\hline & & $\mathrm{B}$ & Std. Error & & & \\
\hline \multirow[t]{4}{*}{$\overline{1}$} & (Constant) & 1.434 & 1.083 & & 1.325 & .188 \\
\hline & $\mathrm{X} 1$ & .073 & .049 & .229 & 1.471 & .144 \\
\hline & $\mathrm{X} 2$ & -.053 & .037 & -.223 & -1.444 & .152 \\
\hline & X3 & -.004 & .032 & -.018 & -.136 & .892 \\
\hline
\end{tabular}

Dari hasil uji Glejser di atas Maka disimpulkan berdasarkan uji Glejser pada SPSS 22, bahwa 2 variabel yakni variabel pendidikan ekonomi keluarga, teman pergaulan dan literasi ekonomi dalam penelitian ini tidak mengalami gejala masalah heterokedastisitas.

\section{Uji Multikolinieritas}

Uji multikolinieritas berfungsi untuk mengetahui ada atau tidaknya penyimpangan asumsi klasik yang berupa adanya hubungan linier antara variabel independen dalam model regresi. Apabila suatu model ditemukan memiliki kesalahan standar yang besar sehingga koefisien tidak dapat dilakukan penaksiran.

Tabel 3. Hasil Uji Multikolinearitas

Coefficients $^{\mathrm{a}}$

\begin{tabular}{|c|c|c|c|c|c|c|c|}
\hline \multirow[b]{2}{*}{ Model } & \multicolumn{2}{|c|}{$\begin{array}{c}\text { Unstandardized } \\
\text { Coefficients }\end{array}$} & \multirow{2}{*}{$\begin{array}{c}\begin{array}{c}\text { Standardized } \\
\text { Coefficients }\end{array} \\
\text { Beta } \\
\end{array}$} & \multirow[b]{2}{*}{$\mathrm{t}$} & \multirow[b]{2}{*}{ Sig. } & \multicolumn{2}{|c|}{ Collinearity Statistics } \\
\hline & $\mathrm{B}$ & Std. Error & & & & Tolerance & VIF \\
\hline $\begin{array}{ll}1 & \text { (Constant) }\end{array}$ & -3.905 & 1.575 & & -2.479 & .015 & & \\
\hline $\mathrm{X} 1$ & .171 & .072 & .208 & 2.382 & .019 & .419 & 2.385 \\
\hline $\mathrm{X} 2$ & .204 & .053 & .332 & 3.814 & .000 & .423 & 2.363 \\
\hline X3 & .261 & .047 & .414 & 5.619 & .000 & .588 & 1.699 \\
\hline
\end{tabular}

Dari hasil pengujian menggunkan SPSS 22 didapatkan hasil seperti didalam tabel diatas. Maka dapat diasumsikan tidak terjadi masalah multikolinearitas karena didapat hasil;

1. Nilai VIF pendidikan ekonomi keluarga $2.385<10$

2. Nilai VIF teman pergaulan $2.363<10$

3. Nilai VIF literasi ekonomi $1.699<10$

Maka disimpulkan bahwa semua data tidak ada masalah, karena semua nilai VIF dibawah standar nilai 10 .

\section{Uji Hipotesis}

\section{Pengaruh Pendidikan Ekonomi Keluarga Terhadap Literasi}

Untuk menguji pendidikan ekonomi keluarga $\left(\mathrm{X}_{1}\right)$ dengan literasi $(\mathrm{Y})$ penulis menggunakan SPSS 22 dengan hasil sebagaimana disajikan pada tabel berikut. 
Tabel 4. Hasil Uji Hipotesis Pertama Coefficients $^{\mathrm{a}}$

\begin{tabular}{|c|c|c|c|c|c|c|}
\hline \multirow{2}{*}{\multicolumn{2}{|c|}{ Model }} & \multicolumn{2}{|c|}{ Unstandardized Coefficients } & \multirow{2}{*}{$\begin{array}{c}\text { Standardized } \\
\text { Coefficients } \\
\text { Beta }\end{array}$} & \multirow[b]{2}{*}{$\mathrm{t}$} & \multirow[b]{2}{*}{ Sig. } \\
\hline & & B & Std. Error & & & \\
\hline \multirow[t]{2}{*}{1} & (Constant) & 15.422 & 3.063 & & 5.036 & .000 \\
\hline & $\mathrm{X} 1$ & .781 & .105 & .600 & 7.422 & .000 \\
\hline
\end{tabular}

Dari tabel diatas diketahui bahwa terdapat pengaruh langsung sebesar 0,600, signifikan pada 0.000 .

Persamaan regresinya

$\mathrm{Y}=\mathrm{a}+\mathrm{bx}$

$\mathrm{Y}=15.422+0.781 \mathrm{x}$

Maka setiap penambahan pendidikan ekonomi keluarga sebesar 1 maka akan berpengaruh kepada literasi sebesar 0,781. Dari out put di atas terlihat nilai $t$ hitung $=7.422$ dengan nilai signifikan $0.000<0.05$, sedangkan nilai t tabel untuk 100 sampel $=1.983$ maka $t$ hitung > t tabel yaitu $7.422>1.983$ maka hipotesis nol ditolak dengan kata lain terdapat pengaruh positif yang signifikan antara pendidikan ekonomi keluarga terhadap literasi.

\section{Pengaruh Teman Pergaulan Terhadap Literasi}

Untuk menguji teman pergaulan (x2) dengan literasi (Y) penulis menggunakan SPSS 22 dengan hasil sebagaimana disajikan pada tabel berikut.

Tabel 5. Hasil Uji Hipotesis Kedua Coefficients $^{\mathrm{a}}$

\begin{tabular}{|c|c|c|c|c|c|c|}
\hline \multirow{2}{*}{\multicolumn{2}{|c|}{ Model }} & \multicolumn{2}{|c|}{ Unstandardized Coefficients } & \multirow{2}{*}{$\begin{array}{c}\text { Standardized } \\
\text { Coefficients } \\
\text { Beta }\end{array}$} & \multirow[b]{2}{*}{$\mathrm{t}$} & \multirow[b]{2}{*}{ Sig. } \\
\hline & & $\mathrm{B}$ & Std. Error & & & \\
\hline \multirow[t]{2}{*}{1} & (Constant) & 14.713 & 3.198 & & 4.600 & .000 \\
\hline & $\mathrm{X} 2$ & .580 & .079 & .595 & 7.327 & .000 \\
\hline
\end{tabular}

Dari tabel diatas diketahui bahwa terdapat pengaruh langsung sebesar 0,595 dengan signifikan pada 0.000 .

Persamaan regresinya

$\mathrm{Y}=\mathrm{a}+\mathrm{bx}$

$\mathrm{Y}=14.713+0.580 \mathrm{x}$

Maka setiap penambahan teman pergaulan sebesar 1 maka akan berpengaruh kepada nilai niat berwirausaha sebesar 0,580. Dari out put di atas terlihat nilai t hitung $=7.327$ dengan nilai signifikan $0.000<0.05$, sedangkan nilai t tabel untuk $100 \mathrm{sampel}=1.983$ maka $\mathrm{t}$ hitung > t tabel yaitu $7.327>1.983$ maka hipotesis nol ditolak dengan kata lain terdapat pengaruh positif yang signifikan antara teman pergaulan terhadap literasi. 


\section{Pengaruh Pendidikan Ekonomi Keluarga dan Teman Pergaulan terhadap Literasi}

Tabel 6. Hasil Uji Hipotesis Ketiga

\begin{tabular}{|ll|r|r|r|r|r|}
\hline Model & & Sum of Squares & df & Mean Square & F & Sig. \\
\hline 1 & Regression & 626.140 & 2 & 313.070 & 88.686 & $.000^{\mathrm{b}}$ \\
& Residual & 342.420 & 97 & 3.530 & & \\
& Total & 968.560 & 99 & & & \\
\hline
\end{tabular}

a. Dependent Variable: $Y$

b. Predictors: (Constant), X3, X1

Dari tabel diatas terlihat bahwa nilai uji $\mathrm{F}$ adalah 88.686 sedangkan nilai $\mathrm{F}$ tabel untuk sampel 100 adalah 2.70. maka nilai $\mathrm{F}$ hit $>\mathrm{F}$ tabel atau $88.686>2.70$ dan nilai signifikan 0.000 ini lebih $<$ dari 0,05. Dapat ditarik kesimpulan bahwa Ho ditolak dan H1 diterima

\section{Pembahasan}

\section{Pendidikan Ekonomi Keluarga Terhadap Literasi}

Berdasarkan pengujian hipotesis yang dilakukan, pendidikan ekonomi keluarga berpengaruh positif terhadap literasi. Hasil ini diperoleh nilai t hitung sebesar $7.422>1.983$ maka secara parsial pendidikan ekonomi keluarga memiliki pengaruh terhadap literasi. Oleh karena itu maka hipotesis nol ditolak, artinya secara parsial pendidikan ekonomi keluarga memiliki pengaruh terhadap literasi.

\section{Teman Pergaulan Terhadap Literasi}

Berdasarkan pengujian hipotesis yang dilakukan, teman pergaulan berpengaruh positif terhadap literasi. Hasil ini diperoleh nilai t hitung sebesar $7.327>1.983$ maka secara parsial teman pergaulan memiliki pengaruh terhadap literasi. Oleh karena itu maka hipotesis nol ditolak, artinya secara parsial teman pergaulan memiliki pengaruh terhadap literasi.

\section{Pendidikan Ekonomi Keluarga , Teman Pergaulan literasi terhadap literasi.}

Berdasarkan hasil olah data penelitian, telah ditemukan bahwa terdapat pengaruuh yang positif dan signifikan antaran pendidikan ekonomi keluarga, Teman Pergaulan terhadap Literasi mahasiswa Universitas Jambi.

\section{KESIMPULAN DAN SARAN}

\section{Kesimpulan}

Berdasarkan hasil penelitian dan pembahasan dalam penelitian ini, maka dapat disimpulkan sebagai berikut:

1. Pendidikan ekonomi keluarga memiliki pengaruh yang positif dan signifikan terhadap literasi ekonomi mahasiswa universitas jambi. Hal ini menunjukan bahwa, jika mahasiswa ingin meningkatkan literasi ekonomi melalui pendidikan ekonomi keluarga, maka dapat dilakukan dengan cara menggali informasi keberhasilan ekonomi suatu keluarga yang bergelut dibidang usaha dan mencari pemecahan masalah atas kegagalan ekonomi suatu keluarga.

2. Teman pergaulan memiliki pengaruh yang positif dan signifikan terhadap literasi ekonomi mahasiswa universitas jambi. Hal ini menunjukan bahwa, jika mahasiswa 
ingin meningkatkan literasi ekonomi melalui teman pergaulan maka dapat dilakukan dengan cara menggali informasi dengan cara wawancara, sering, diskusi mengenai pengalaman keberhasilan teman yang bergelut dibidang usaha.

3. Pendidikan ekonomi keluarga, Teman pergaulan terhadap Literasi ekonomi. Hal ini menjelaskan bahwa jika mahasiswa universitas jambi memiliki pendidikan ekonomi keluarga yang baik mengenai kewirausahaan berupa adanya ketertarikan terhadap dunia wirausaha, memperhatikan segala sesuatu yang berhubungan dengan kewirausahaan, serta adanya keterlibatan secara aktif pada kegiatan yang berhubungan dengan kewirausahaan, maka dengan sendirinya mahasiswa pun akan berniat untuk berwirausaha

\section{Saran-saran}

Berdasarkan beberapa kesimpulan yang diperoleh, maka saran untuk dimasa mendatang sebagai berikut:

1. Diharapkan kedepan mahasiswa harus bisa memanfaatkan waktu sebaik baik mungkin ketika mereka masih duduk bangku perguruan tinggi untuk mengembangkan potensi diri dengan arahan, bimbingan dan saran dosen membuat agar lebih giat belajar dan berlatih kewirausahaan dengan memanfaatkan fasilitas kewirausahaan yang ada selama dibangku kuliah. Karena dengan begitu diharapkan dapat menumbuhkan kesiapan mereka yang lebih baik lagi untuk menjadi seorang entreprenuership.

2. Diharapkan kedepan dosen pada FKIP Universitas Jambi mampu memberikan dorongan kepada mahasiswa/inya untuk menuangkan ide-ide atau gagasan yang mereka miliki untuk dijadikan sebuah karya nyata, dan itu semua harus di mulai dari bangku kuliah, agar mahasiswa/i nantinya menjadi terbiasa hingga mereka menyelesaikan pendidikan dari peguruan tinggi dan mampu menjadi seorang wirausaha yang mandiri tanpa harus mencari pekerjaan lagi.

3. Diharapkan kedepan dosen pada FKIP Universitas Jambi mampu memberikan dorongan kepada mahasiswa/Inya dalam upaya meningkatkan keyakinan diri dan rasa percaya diri mahasiswanya untuk berwirausaha. Karena untuk menjadi seorang entrepreneurship yang sukses efikasi diri yang tinggi sangat dibutuhkan sekali, dengan memiliki efikasi diri yang tinggi seseorang akan mampu mengatasi setiap permasalahan yang ada, akan selalu bersemangat dalam menghadapi tantangan dalam usaha, serta akan terus berinovasi agar usaha yang dijalankan dapat berkembang pesat.

4. Diharapkan kedepan dosen maupun pihak kampus mampu menanamkan sikap optimis pada mahasiswa/i agar mau dan mampu untuk berwirausaha. Secara Akademis:

Kesiapan berwirausaha mahasiswa/I Fakultas Keguruan dan Ilmu Pendidikan (FKIP) Universitas Jambi dapat dipengaruhi oleh faktor lain, oleh karena itu perlu kajian yang lebih komfrehensif, guna menjawab faktor lain (epsilon) yang mempengaruhi kesiapan berwirausaha mahasiswa selain dari kreativitas, efikasi diri dan motivasi berwirausaha.

\section{DAFTAR RUJUKAN}

Ahvenainen, Raija. (2003). Modern Plastics Handbook (edisi ke-1st). Woodhead Publishing Limited. hlm. 24.1. 
Anastasios Xepapadeas (2008). "Ecological economics". The New Palgrave Dictionary of Economics 2 nd Edition. Palgrave MacMillan.

Anggraini, Ranti Tri dan Santhoso, Fauzan Heru. 2017. Hubungan antara Gaya Hidup Hedonis dengan Perilaku Konsumtif pada Remaja. Gadjah Mada Journal Of Psychology Volume 3, No. 3, 2017: 131-140

Alma, Buchari. 2011. “Kewirausahaan”. Bandung: Alfabeta

Aslaksen, Iulie; Bragstad, Torunn; Ås, Berit (2014). "Feminist Economics as Vision for a Sustainable Future". Dalam Bjørnholt, Margunn; McKay, Ailsa. Counting on Marilyn Waring: New Advances in Feminist Economics. Demeter Press/Brunswick Books. hlm. 21-36. ISBN 9781927335277.

Backhaus, J., Breukers, S., Paukovic, M., Mourik, R., \& Mont, O. (2011). Sustainable lifestyles: Today's facts \& tomorrow's trends. Wuppertal. Germany.

Fai Chow, Cheuk; Mui Winnie So, Wing; Yan Cheung, Tsz; and Kit Dennis Yeung, Siu. 2017. Plastic Waste Problem and Education for Plastic Waste Management. (C) Springer Nature Singapore Pte Ltd. 2017; S.C. Kong et al. (eds.), Emerging Practices in Scholarship of Learning and Teaching in a Digital Era, DOI 10.1007/978-981-10-33445_8

Fraj, Elena and Martinez, Eva (2006) Environmental values and lifestyles as determining factors of ecological consumer behaviour: an empirical analysis. Journal of Consumer Marketing. Vol 23, Nomor 3 Pp 133-144

Hariyono, P. (2015). Hubungan gaya hidup dan konformitas dengan perilaku konsumtif pada remaja siswa Sekolah Menengah Atas Negeri 5 Samarinda. eJournal Psikologi, 3(2),569-578.

Heflin, F.Z. 20011. Be a entrepreneur (jadilah seorang wirausaha) Kajian strategis pengembangan wirausaha. Yougyakarta: Graha Ilmu.

Imawati, I., Susilaningsih, \& Elvia, I. 20013. Pengaruh finansial literasi terhadap perilaku konsumtif Remaja pada Program IPS SMA Negeri 1 Surakarta Tahun Ajaran 2012/2013. Jupe UNS, Vol 2 No. 1 Hal. 48

Jeroen C.J.M. van den Bergh (2001). "Ecological Economics: Themes, Approaches, and Diffe-rences with Environmental Economics," Regional Environmental Change, 2(1), pp. $13-23$

Koranti, Komsi. 2013. "Analisis pengaruh Faktor Eksternal dan Internal terhadap minat berwirausaha”. Dalam Prosiding PESAT vol 05 No.05 Hal E1-E8. Bandung: Universitas Gunadarma.

Malte Faber. (2008). How to be an ecological economist. Ecological Economics 66(1):1-7. Preprint.

Muhibbin Syah. (1999). Psikologi umum dengan pendekatan Baru. Bandung: Remaja Rosda Karya.

Nurkholis, 2013. PENDIDIKAN DALAM UPAYA MEMAJUKAN TEKNOLOGI. Jurnal Kependidikan, Vol. 1 No. 1 Nopember 2013 hal. 24-44.

Nurmiyati. 2002, Faktor Determinan Minat Wirausaha Mahasiswa Fakultas Ekonomi dan Bisnis Universitas Negeri Gorontalo” Dalam jurnal Trikonomika, Volume 13 No.1. Hal 78-90 
Purwaningrum, Pramiati., (2016) Upaya Mengurangi Timbulan Sampah Plastik Di Lingkungan. Junal Teknik Lingkungan Vol 8 No.2, Desember 2016, hal. 141-147

Robbins SP, dan Judge., 2008."Perilaku Organisasi,Jilid 2".Jakarta:Indeks Kelompok Gramedia.

Røpke, I. (2009). The role of consumption in global warming-an ecological economic perspective. Anthology on global warming. Routledge.

Santiago, F. (2014, January). Strategi Pemberantasan Tindak Pidana Korupsi Kajian Legal Sosiologis.

Santoso, L., \& Meyrasyawati, D. (2015). Model Strategi Kebudayaan dalam Pemberantasan Korupsi di Indonesia. Jurnal Review Politik, 5 (01), 22-45.

Sari, G.L., 2017. Kajian Potensi Pemanfaatan Sampah Plastik Menjadi Bahan Bakar Cair. AlArd: Jurnal Teknik Lingkungan Vol.3 No.1 - Agustus 2017 Hal. 6-13.

Septiani, B.A dan Arian, D,M., Risman, A.F.A.A., Handayani, B., dan Kawuryan, I.S.S., 2019. Pengelolaan Sampah Plastik di Salatiga: Praktik dan Tantangan. Jurnal Ilmu Lingkungan (2019), Vol. 17 Nomor 1: Hal. 90-99, ISSN 1829-8907.

Shandy, Bagus. 2013. Pengaruh Pendidikan Ekonomi Keluarga TerhadapPperilaku Konsumsi Dimediasi literasi Ekonomi dan Gaya Hidup pada Mahasiswa Universitas Malang. Vol 1, No. 1, Desember 2013.

Slameto. (2007). Belajar dan Faktor-faktor yang mempengaruhinya. Jakarta: Pt Rineka Cipta.

Slavin, Robert, 2008. Psikologi pendidikan teori dan praktek. Jakarta. PT indeks

Soderbaum, P. 2008. Understanding Sustainability Economics. Earthscan, London. ISBN 978-1-84407-627-7. pp.109-110, 113-117.

Suryani, T. 2008. Perilaku konsumen: implikasi pada strategi pemasaran. Yogyakarta: graha ilmu.

unep.org/wed/greeneconomy, Towards Green Economy, diunduh 3 Januari 2020

Untoro Budi Surono ${ }^{1 *}$ dan Ismanto ${ }^{1}$ Univ. Janabadra Yogyakata. 2016. Pengolahan Sampah Plastik Jenis PP, PET dan PE Menjadi Bahan Bakar Minyak dan Karakteristiknya. Jurnal Mekanika dan Sistem Termal (JMST) Vol. 1(1)2016:32-37.

Victor, Peter. (2008). Book Review: Frontiers in Ecological Economic Theory and Application. Ecological Economics 66(2-3).

Wardani, N. S. (2015). Pengembangan Nilai-Nilai Budaya Sekolah Berkarakter. Scholaria: Jurnal Pendidikan Dan Kebudayaan, 5(3), 12-22.

Wedayani, Ni Made, 2018.Studi Pengelolaan Sampah Plastik Di Pantai Kuta Sebagai Bahan Bakar Minyak. Jurnal Presipitasi: Media Komunikasi dan Pengembangan Teknik Lingkungan Vol.15 No.2 September 2018. Hal. 122-126.

$\underline{\mathrm{Xu}}, \mathrm{X} ., \underline{Y}$ Yo, Z. and Sun, Q. (2019), "Social media environments effect on perceived interactivity: An empirical investigation from WeChat moments", Online Information Review, Vol. 43 No. 2, pp. 239-255. https://doi.org/10.1108/OIR-12-2016-0344

Yeung, S., So, W., Cheng, N., Cheung, T. and Chow, C. (2017), "Comparing pedagogies for plastic waste management at university level", International Journal of Sustainability in Higher Education, Vol. 18 No. 7, pp. 1039-1059. https://doi.org/10.1108/IJSHE-042016-0073

Yuniarti, V. S. (2015). Perilaku konsumen -teori dan praktik. Bandung: Pustaka Setia. 
Zhang, Y., Deng, J., Majumdar, S., \& Zheng, B. (2009). Globalization of lifestyle: Golfing in China. In H. Lange \& L. Meier (Ed.), The new middle classes: Globalizing lifestyles, consumerism and environmental concern (hal. 143-158). London and New York: Springer. https://doi.org/10.1007/978-1-4020-9938-0 